\section{HUMAN PAPILLOMA VIRUS AND OTHER RISK FACTORS OF CARCINOMA CERVIX}

S. Khatun', Syed Md Akram Hussain², F. Hossain ${ }^{3}$, A. Choudhury ${ }^{4}$

\section{Abstract:}

Cervical cancer is the most common cancer among women in many developing countries constituting 20\%-30\% of female cancers. The etiological factors of cervical cancer include environmental, social, sexual and sexually transmitted agents including human papilloma virus (HPV).HPV has identified in $99.7 \%$ invasive cancer .Objective of the study was to find out the prevalence of HPV-DNA virus among diagnosed cases of preinvasive and invasive diseases and to find out different sociodemographic parameters related to carcinoma cervix. This was a cross sectional study. The study has conducted in the department of Obstetrics and Gynaecology of Bangabandhu Sheikh Mujib Medical University. Duration of study was from May 2005 to May 2006. Samples were collected from diagnosed cases of CIN I, II, III and CIS and invasive cancer. Thirty cases were recruited for collection of cervical scraping. Sample were collected of in a specially designed sampler containing liquid transport medium and preserved in minus 20 Degree Celsius and sent to the DNA laboratory for processing and identification of HPV by hybrid capture II method. The results were analyzed by using SPSS version 11.0 and shown in tables and diagrams. The risk factors for HPV infection identified from the result. These are early sexual activity, years of sexual activity, urban people, and higher number of pregnancies. The test could identify HPV-DNA in $100 \%$ of invasive and $50 \%$ of preinvasive cancer. In this study HPV infection was found as a strong determinant for the development of cervical carcinoma and its precursors. Poor socio-economic condition, lower level of education, early marriage and first delivery, multi-parity, years of sexual activity are the risk factors for developing HPV infection. New guidelines for cervical cancer screening strategies

1. Professor, Gynaecological Oncology Unit, Dept of Obstetrics and Gynaecology, Bangabandhu Sheikh Mujib Medical University, Dhaka, Bangladesh.

2. Professor and Chairman, Department of Oncology, Bangabandhu Sheikh Mujib Medical University, Dhaka, Bangladesh.

3. Assistant Professor, Dept. of Obst. and Gynaecologyy. Bangabandhu Sheikh Mujib Medical University, Dhaka, Bangladesh.

4. Research Assistant, Dept. of Obst and Gynaecology. Bangabandhu Sheikh Mujib Medical University, Dhaka, Bangladesh. could be able to develop from the information obtained from this study. A population-based study with larger sample will be required for the evaluation of cervical cancer screening strategies.

Key words: HPV, Carcinoma Cervix

\section{Introduction:}

Cervical cancer is the second commonest cancer among the women globally, accounting for $15 \%$ of all female cancer. It is the most common cancer among women in many developing countries is around $20-30 \%$. In western countries, it accounts for only $4-6 \%{ }^{1-4}$.This differences largely reflect the impact of mass screening using cervical cytology methods ${ }^{5}$.Limitation of traditional cytological screening remains a source of high rate of false negative results. A meta-analysis of 28 studies in which conventional cytology was evaluated for the accuracy as a screening test, reported as mean sensitivity and specificity of $58 \%$ and $59 \%$ respectively 6 . Problem identified of such screening programs in the poor countries are cost, availability of technology and trained clinicians, and adequate infrastructure to track women with abnormal smear findings ${ }^{7}$. Recognition of strong causal relationship between persistent infection of the genital tract with high risk Human Papilloma Virus and occurrence of cervical cancer ${ }^{8,9}$ has resulted in the experimental and industrial development of HPV detection systems. Detection of high risk HPV-DNA considered useful in three clinical applications. First, as a primary screening test solely or in combination with a Pap's smear to detect cervical cancer precursors. Second, as a triage test to select women showing minor cytological lesions in their Paps smear needing referral for diagnosis and treatment. Third, as a follow-up test for women being treated fro high-grade intraepithelial lesion to predict cure or failure of treatment ${ }^{10}$.

Cervical cancer is preceded by precancerous changes which represent \& continuum of morphologic change beginning with CIN I and progressing through CIN II and CIN III to invasive carcinoma. They may not invariably progress to cancer and a good number of them may spontaneously regress. The persistent and severity of the precancerous change influence the progress of the disease. The likelihood of regression of CIN I, CIN II and CIN III is $60 \%$, 40 \%, 33\% respectively and progression to invasive cancer is $1 \%, 5 \%$ and greater than 12 $\%$ respectively. The time lag between infection and development of invasive cancer varies and apparently on average more than 15 years $^{11}$. 
Zur Hausen for the first time suggested the association between HPV and genital cancer . It received little attention from researchers and epidemiologists prior to 1988. Several studies later established HPV infection as a sexually transmitted disease and major risk factor for development of CIN and invasive cancer. Studies revealed that cervical dysplasia and cancer usually arises among women with persistent HPV infection ${ }^{12}$. By the year 1992, HPV has been clearly established as the primary cause of cervical cancer in nearly all cases ${ }^{13}$.

Certain types of human papilloma virus has been emerged as the most likely infectious agent causing atypical transformation of squamo-columner junction and are well established as the primary cause of cervical cancer. Several studies have shown that HPV testing can improve the detection rate of high grade cervical intraepithelial neoplasia (CIN), but these have been carried out primarily in younger women.

Main oncogenic strains are :types16 and 18 . Other types, 31,33,51,52, 35 and 58 are intermediate risk HPV, and low risk HPV are 6,11,42,43 and 44. HPV is a small double stranded DNA virus with protein capsid . About 120 types of HPV has been described.The circular viral genome has been divided into 3 regions .Upstream regulatory region, early region E1, E2, E3,E4, E5,E6,E7 and late region L1,L2, E6 and E7 are responsible for oncogenic properties of HPV. Around $75 \%$ sexually active women are infected. Genital tract micro trauma enhances viral entry into host cells. E6 and E7 proteins block natural control of growth of cervical cells. Integration of viral genome occurs into host cell DNA. Mutation may occur in the cervical cell leading to precancer and cancer respectively.

Cervical cancer gives opportunities for its control through screening because cervix is a surface organ, easily accessible and it has a long premalignant phase. If CIN are identified and treated, the lesions do not develop into invasive cancer. At present, methods available for cervical cancer screening includes cytology based screening, colposcopy, unaided visual inspection including visual inspection of cervix after application of acetic acid (VIA ) and tests for HPV markers ( PCR and Hybrid capture II ). The Hybrid capture II method of HPV detection which has been carried out in this study is known as Digene Diagnostics. It is a linear signal amplified hybridization antibody capture microplate adday . The HC II test involves a laboratory process that produces light signals roughly proportional to the amount of HPV DNA present in the specimen.

Semi quantitative detection of eighteen types of HPV DNA in cervical specimen can be carried out . For detection of high grade dysplasia , the sensitivity range of this test has been recorded as 80-90\% and specificity has ranged from 57-89\% (14)..

Our country is developing efficient screening program to reduce the incidence of cervical cancer and its related mortality and morbidity. It is also necessary to find out different risk factors related to this cancer in its own environmental, social and cultural background.

\section{Materials and methods:}

\section{Methodology:}

Women aged between 20 and 65 years who attended the gynaecology outpatient depertment and colposcopy clinic of Bangabandhu Sheikh Mujib Medical University were asked to join a study in which HPV testing would be performed Informed consent was obtained from all participants after oral explanation of the study and was provided by the research assistant.

Method of specimen collection: 30 patients who were diagnosed as a case of chronic cervicitis, cervical intraepithelial neoplasia or invasive cancer by VIA, Paps smear followed by colposcopy and colposcopy directed biopsy were recruited as study cases. Endocervical scraping from all these study cases were taken by the brush of the Digene sampler. This specimen for HPV DNA testing were suspended in $1 \mathrm{ml}$ of transport medium [Digene] and stored at -20 degree C until further processing. All scrapes were analysed for the presence of HR - HPV types, 16,18, 31,33,35,39,45,51,52,56,58,59 and 68. The test result was given as HPV positive or negative for high risk Human Papilloma virus . The results were noted in a performed data collection sheet in which all the particurals of the patients regarding socioeconomic status, marital status, results of Paps smear, VIA test and colposcopy reports were collected. Finally the results of the test were compiled and statistically analysed using SPSS version.11.0. Results are shown in tables and graphs.

\section{Results :}

Results collected from diagnosed cases of chronic cervicitis , CIN I, II, III and invasive cancer. HPV identification done from 30 samples. 
Table - I : Age of the patients, age of the initiation of sexual activity and years of sexual activity.

\begin{tabular}{|c|c|c|c|c|c|c|c|c|}
\hline \multicolumn{3}{|c|}{ Age of Patients } & \multicolumn{3}{|c|}{ Age of first intercourse } & \multicolumn{3}{|c|}{ Total Years - sexual activity } \\
\hline Age of range & Frequency & Percentage & Age of range & Frequency & Percentage & Age range & Frequency & Percentage \\
\hline $20-29$ & 7 & $23.3 \%$ & $12-13$ & 5 & $16.66 \%$ & $6-12$ & 7 & $23.3 \%$ \\
\hline $30-39$ & 9 & $30.0 \%$ & $14-15$ & 8 & $26.66 \%$ & $13-19$ & 10 & $33.3 \%$ \\
\hline $40-49$ & 9 & $30.3 \%$ & $16-17$ & 14 & $46.66 \%$ & $20-26$ & 2 & $6.7 \%$ \\
\hline $50-59$ & 4 & $13.3 \%$ & $18-20$ & 1 & $3.33 \%$ & $27-32$ & 6 & $20.0 \%$ \\
\hline \multirow[t]{2}{*}{$60-69$} & 1 & $3.3 \%$ & $20-25$ & 2 & $6.66 \%$ & 33-39 & 3 & $10.0 \%$ \\
\hline & & & & & & Missing & 2 & $6.7 \%$ \\
\hline
\end{tabular}

Table-I: shows the age distribution of the patients. Range was 20-65 years. Mean age (37.63+- 11.053). These cases were of chronic cervicitis upto invasive carcinoma, so age range was large. The table also shows the age of first intercourse and total years of sexual activities.

?? Output

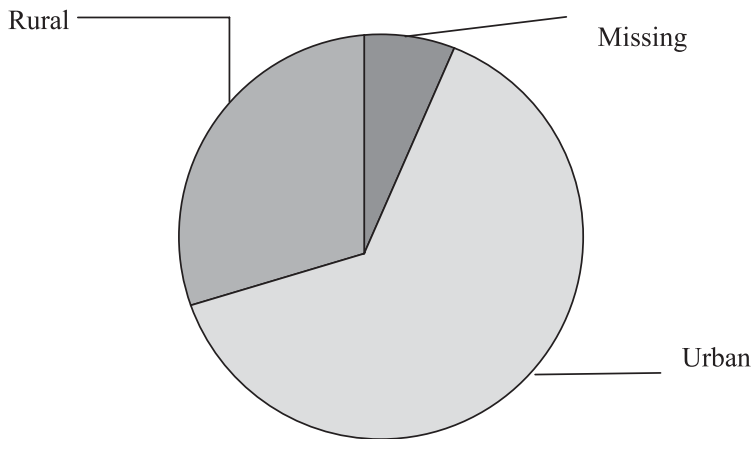

Fig.-1 : Distribution of residence of respondence.

Figure-I: A pie chart shows distribution of residents of the respondents. More than $50 \%$ women came from urban area. As it is a sexually transmitted disease, it was common in urban women. shows distribution of age of initiation of sexual activity. Mean age of the patients at which sexual activity was started was 16.07 years. Sixty seven percent patients were sexually active at 15,16 or 17 years of their age.

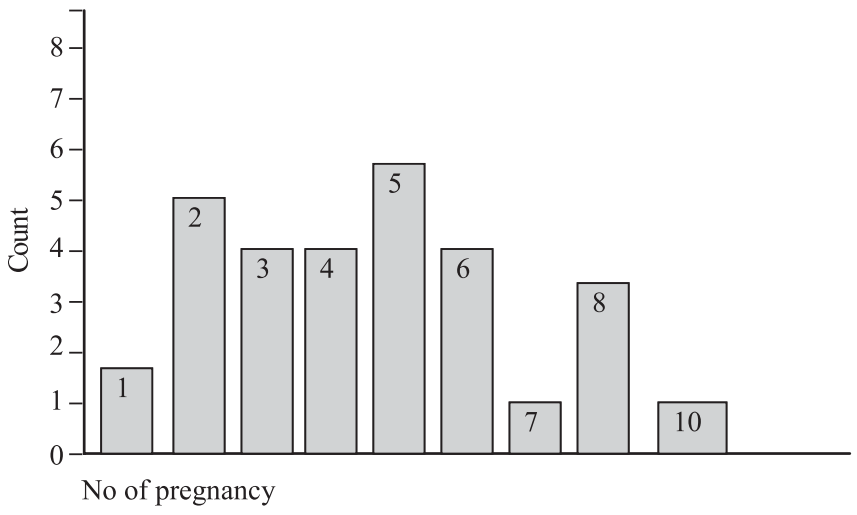

Fig.-2 : Distribution of no of pregnancy

Figure-2 showed that about $90 \%$ patients had more than 5 pregnancies. It is well established that every pregnancy causes trauma to the genital tract, which is susceptible to HPV infection.

Table-II : Residence and living status of the patients.

\begin{tabular}{lccccc}
\hline & Residence & & \multicolumn{3}{c}{ Living Status } \\
Residence & Frequency & Percentage & Living Status & Frequency & Percentage \\
\hline Urban & 20 & $66.66 \%$ & Middle Class & 21 & $70.00 \%$ \\
Rural & 9 & $33 \%$ & Poor & 8 & $26.66 \%$ \\
Missing & 1 & $3.33 \%$ & Rich & 1 & $3.33 \%$ \\
\hline
\end{tabular}

Table-II showed distribution of living status of husbands. $70 \%$ patients were of middle class, only $3.33 \%$ rich. These findings also indicate that living status is related with HPV infection and Carcinoma cervix. Rest of the women belongs to poor class family. So 95 $\%$ patients were of parts of middle class. 
Table-III : Relationship of biopsy report and HPV DNA report crosstabulation

\begin{tabular}{lccc}
\hline Biopsy Report & \multicolumn{2}{c}{ HPV Report } & \multirow{2}{*}{ Total } \\
\cline { 2 - 3 } & Positive & Negative & \\
\hline Chronic cervicities koiloytic change & 0 & $10 \%$ & 3 \\
Carcinoma in situe & 0 & $3 \%$ & 1 \\
CIN1 & $7 \%$ & $37 \%$ & 13 \\
CIN2 & $10 \%$ & $23 \%$ & 10 \\
Invasive & $10 \%$ & 0 & 3 \\
\hline Total & $27 \%$ & $73 \%$ & 30 \\
\hline
\end{tabular}

Table-III shows distribution of biopsy report and HPV DNA report cross tabulation count. This table shows that higher the severity of the disease more the prevalence of HPV DNA virus positivity. Theses findings were analyzed by pearson chi-square test (P-value .031) which is statistically highly significant .
Table-IV : Distribution of VIA report and HPV DNA identification report

\begin{tabular}{lccc}
\hline HPV DNA & \multicolumn{2}{c}{ VIA Report } & Total \\
\cline { 2 - 3 } & Positive & Negative & \\
\hline Positive & 6 & 2 & 8 \\
Negative & 21 & 1 & 22 \\
\hline Total & 27 & 3 & 30 \\
\hline
\end{tabular}

Table-IV shows relationship of HPV DNAreport and VIA report. VIA and HPV DNA results are significant at $90 \%$ confidence interval and $P$ value is .099.

Table-V : Identified the risk factors by the regression analysis Regression of Coefficient $(R=.621)$

\begin{tabular}{llll}
\hline Risk factors & $\begin{array}{l}\text { Unstandarized } \\
\text { coefficient } \\
\end{array}$ & B & \multicolumn{2}{c}{$\begin{array}{c}\text { Standarized } \\
\text { coefficient }\end{array}$} & Beta \\
\cline { 2 - 4 } Constant & .990 & .962 & .318 \\
Age in years & $9.781 \mathrm{E}-03$ & .024 & .0240 \\
No.of years sexually active & $6.882 \mathrm{E}-03$ & .022 & .150 \\
Living status of husband & $8.822 \mathrm{E}-03$ & .309 & .009 \\
Socioeconomic status & .166 & .223 & .179 \\
No.of pregnancy & $-7.417 \mathrm{E}-02$ & .058 & -.376 \\
VIA report & -.534 & .315 & -.383 \\
Age of first intercourse & $4.535 \mathrm{E}-02$ & .035 & .294 \\
Occupation of husband & $-5.592 \mathrm{E}-02$ & .083 & -.163 \\
Biopsy report & .101 & .091 & .244 \\
\hline
\end{tabular}

Table-V shows the risk factors for HPV DNA positive cases. By regression coefficient ( $\mathrm{R}=.621$ ) analysis it is found that factors like age of the patient, socioeconomic condition, years of sexual activity, no. of pregnancy, age of onset of sexual activity all are risky for HPV DNA infection.

\section{Discussion:}

Invasive Cervical carcinoma is the second commonest malignancy in women wprldwide accounting for about 500000 deaths per year. In the UK the incidents is 9.3 per 100000 women per year, this figure has fallen $26 \%$ since $1992^{16}$.

The major risk factor for cervical cancer is the Human Papilloma Virus (HPV) of which HPV types 16 and 18 are the high risk types. Vital integration into the host genome and the binding of tumor suppressor gene protein $\mathrm{p} 53$ and Rb by the E6 and E7 proteins of high risk vital types are key events in viral oncogenesis.

The presence of HPV DNA is found in almost $100 \%$ of cervical carcinomas and over $60 \%$ of cervical intraepithelial neoplasia ${ }^{17}$.
It is this close association that has led to the possibility of using screening for HPV infection as part of cervical cancer screening program.

While many early study demonstrated this association between the disease states and HPV presence, it has only been in the recent past that an attempt has been made to determine the prevalence of HPV infection in the female population. Many studies has shown that HPV infection is commonly acquired after the onset of sexual intercourse. The vast majority of women probably eradicate this infection and it is the persistent of infection that leads to a higher risk for the development of cervical intraepithelial carcinoma. Unfortunately the prevalence rate has meant that there may be limited value in using HPV screening. 
It has been proposed that screening women over the age of 35 may be more specific and more particular the absence of HPV infection may be of important negative predictive value for the risk of developing disease for the future.The transmission of HPV typically occurs through the skin to skin anogenital contact. Increased risk of acquiring HPV has been associate with the multiple sexual partners, younger age of sexual debut, failure to use condoms and sex with uncircumscribed males ${ }^{18}$. However one study reported that $20 \%$ of women became infected with only one lifetime sex partner. Suggesting that both partners must be sexually naïve to prevent infection.

Several studies has shown that the risk of infection increases substantially when initiating a new sexual relationship. The transmission of HPV infection can be bloked by latex condoms if the infected area is physically covered ${ }^{19}$. Another study concluded that malignant disease of the cervix proved at least four times common among the women with gonorrhoea than the controls. It may be assumed that at leats every month women who have gonorrhoea was a carrier of carcinogenic agent ${ }^{20}$. All these findings collaborate the view that cervical carcinoma is a sexually transmitted disease. Factors like reproductive characteristic and genital infections can be interpreted as expressions of sexual behavior. Despite increasing health consciousness and extensive mass screening for cervical cancer, these risk factors play an important role. Women with history of HPV infection, syphilis and gonorrhoea should be considered as risk group and should be followed up to reduce the rate of ICC in screened patients.

The present research work has been undertaken to study the prevalence of HPV among women with ICC, CIN and normal cervix. This study also tried to find out the association of different risk factors for development of ICC and CIN in population. The women were recruited from Gynaecological OPD of BSMMU. The parity number of marriage of husband, years of sexual activity and this drawback produce difficulties in interpretation of results. Multivariate regression analysis helped to overcome these drawbacks to some extent . development of awareness regarding natural history of cervical cancer and importance of cervical examination is of paramount importance for early diagnosis of preinvasive and invasive cervical carcinoma, its prevention and management.

It is observed that there can be variation of HOPV prevalence among control population globally in different countries. Bosch et al showed that there was no difference of HPV prevalence and cervical cancer patients in different countries. But the prevalence of this infection varies distinctly between and within control population ${ }^{21}$. The information of prevalence among the normal population is important in developing national screening program
Primary prevention of cervical cancer through preventing HPV infection by prophylactic vaccines against HPV may contribute against cancer prevalence and the vaccine has already been developed. Vaccination has been accepted as an effective means by which infectious disease can be prevented or eliminated. HPV vaccine will be most effective when administered prior to initiation of sexual activity and vaccination initiatives will most likely target preadolescent and adolescent population.

\section{Conclusion:}

As there is close association between HPV infection and invasive cancer, identification of high risk type could be an important tool for screening of carcinoma cervix. Primary screening procedure if not reliable and feasible for developing country, HPV DNA can strengthen the result. During follow up of preinvasive disease, the test can be less hazardous that colposcopy. In very near future we have to accept the vaccination against the virus. A quadrivalent vaccine for adolescent girls against HPV types 16,18,6 and 11 will significantly reduce persistent infection.

\section{Ackowledgment:}

The project was funded by University Grants Commission. We would to like to thank University Grants Commission. We are grateful to the Chairman, Department of Obstetrics \& Gynaecology for his kind support.

\section{References:}

1. Hanson D, Tarone R. An epidemiologic study of cancer of the cervix, vaginal and vulva based on the Third National Cancer Survey in the United States. Am J Obstet Gyncol 1977; 129: 525-532.

2. Vessey MP. Epidemiology of cervical cancer: role of hormonal factors, cigarette smoking and occupation. Banbury Report 1986 ; 21: 29-43.

3. Armstrong BK, Munoz N, Bosch FX. Epidemiology of cancer of the cervix, In: coppleson M, ed. Gynaecologic oncology Edinburg: Churchill Livingstone, 1992.

4. National Institute of Health, Cervical cancer: NIH concsensus statement, Bethesda, MD: National Institute of Health, 1996 April 1-3; 14: 1-38.

5. Niemien P, Kallio M, Hakama M. The effect of mass screening on the incidence and mortality of squamous and adenocarcinoma of cervix uteri. Obstet Gyncol 1995; 85: 1017-1021.

6. Fahey MT, Irwig L, Macashill P, Meta - analysis of paptest accuracy. Am J Epidemiol 1995; 141: 680-689.

7. Herdman. C. Sherrist. J., 2000, Planning appropriate Cervical Cancer Control Programme. 2ne Ed.Seattle, Washington, PATH. 
8. Bosch FX, Lorincz A, Munoz N, Meijer CJ, Shah KV. The casual relation between human papillomavirus and cervical cancer. J Clin Pathol 2002; 55: 244-65.

9. IARC. Cervix cancer screening: IARC handbooks of cancer prevention, vol. 10. lyon; 2005.

10. Arbyn M, Buntinx, F. Van Ranst M, Cortinas Abrahantes J. Triage of women with atypical or low grade cytological abnormalities of systematic review and meta-analysis. IPH/ EPI - REPORTS Nr. 2001-019. Brussels: Scientific Institute of Public Health ; 2002.p. 1-240.

11. Ostor AG. National institute of cervical intraepithelial neoplasia: a critical review. Int J Gynaecol Pathol 1993; 12 : 2: 186-192.

12. Ho GYF, Burk RD, Klein S, Kadish AS, Chang CJ, Palen P, Basu J, Tachezy R, Lewis R, Romney S. Persistent genital Human Papilloma Virus infection as a risk factor for persistent cervical dysplasia. J Natl Cancer Inst 1995; 87: 1367-1371.

13. Munoj N, Bosch FX. The casual link between HPV and cervical cancer and its implications for prevention of cervical cancer. Bulletin of PAHO 1996; 30: (4) : 362-377.

14. Cuzick J, Terry G, HOL, Hollingworth T and Anderson M. Type specific human papilloma virus DNA in abnormal smears as a predictor of high grade of cervical intraepithelial neoplasia. Br J Cancer 1994; 69: 167-171.
15. C Clavel, M Masure, J-P Bory, et. al. Hybrid Capture II Based Human papilloma Virus detection, High Grade cervical lesion : Apreliminary study on 1518 women, British Journal of cancer (1999) 80 (9), 1306- 1311.

16. Arends MJ, Buckley CH, wells M, Aetiology, pathogenesis and pathology of cervical neoplasia. Journal of clinical pathology 1998; 51: 96-103.

17. Natural history of human papilloma virus infection in young women : a longitudinal cohort study 2001. Lancet 357; p 1831-1836.

18. Ley C, Bauer HM, Reingold A, et. al. Determinants of genital human papilloma virus infection in young women: Journal of the National Cancer Institute. 1991; 83: 9971003.

19. Manhart LE, Koutsky LA. DO condoms prevent genital HPV infection, external genital warts, or cervical neoplasia. A meta- analysis. Sexually transmitted diseases. 2002; 29(11): 725-735.

20. Herrero R, Brinton LA, Reeves WC, Brenes MM, Tenorio F, DE Britton RC, Gaitan E, Garcia M, rawls WE. Sexual behaviour, veneral diseases, hygiene practices, and invasive cervical cancer in a high risk population. Cancer :1990; 65(2): 380-386.

21. Bosch FX, Manos MM, Munoj N, Jansen M, Peto J, Schiffman MH, Moreno V, Kurman R, Shah KV. Prevalence of human papilloma virus in cervical cancer: a world wide perspective. J Natl Cancer Inst 1995; 87: 796-802. 